\title{
Overturning stability of L-shaped rigid barriers subjected to rockfall impacts
}

\author{
Dr Carlos Lam
}

Geotechnical Engineer, Geotechnical Engineering Office, Civil Engineering and Development Department, The Government of the Hong Kong Special Administrative Region, 101 Princess Margaret Road, Ho Man Tin, Hong Kong. Email: carloslam@cedd.gov.hk

Mr Arnold C. Y. Yong (Corresponding Author)

PhD Candidate, Department of Infrastructure Engineering, The University of Melbourne, Parkville, Victoria 3010, Australia. Email: cyyong@ student.unimelb.edu.au. Tel.: +61466602435.

\section{Dr Julian S. H. Kwan}

Chief Geotechnical Engineer, Geotechnical Engineering Office, Civil Engineering and Development Department, The Government of the Hong Kong Special Administrative Region, 101 Princess Margaret Road, Ho Man Tin, Hong Kong. Email: juliankwan@ @ cedd.gov.hk

\section{Prof Nelson T. K. Lam}

Professor, Department of Infrastructure Engineering, The University of Melbourne, Parkville, Victoria 3010, Australia. Email: ntkl@unimelb.edu.au

\section{ACKNOWLEDGEMENTS}

Financial support from the Australian Research Council (ARC) Discovery Project DP170101858 entitled New Approach for Design of Barriers for Impact is gratefully acknowledged. The third author is grateful for financial support from the theme-based research grant T22-603/15-N provided by the Research Grants Council of the Government of the Hong Kong SAR, China. This paper is published with the permission of the Head of Geotechnical Engineering Office and the Director of Civil Engineering and Development of the Government of the Hong Kong SAR. 


\begin{abstract}
s
Reinforced concrete barriers are commonly used as defence measures in hilly areas to contain falling boulders and landslide debris. These barriers are conventionally designed to satisfy the conditions of force and momentum equilibrium with a factor of safety. A major limitation of this approach is that the inertial resistance of the barrier is neglected such that the design could be over-conservative. This paper presents a novel displacement-based approach for the assessment of overturning stability of rigid L-shaped barriers subjected to rockfall impacts. Analytical solutions, which are derived based on conservation of momentum and energy, are used to take into account the contributions of the self-weight and thus the inertial resistance of the barrier in resisting an impact. The actual amount of energy transferred from the impacting boulder to the barrier is considered by including the coefficient of restitution between the two objects. The accuracy of the analytical solutions has been confirmed by laboratory impact experiments. Numerical assessments conducted using the new solutions indicate that a reasonably sized rigid barrier, due to its own inertial resistance, may adequately withstand the impact action of a heavy boulder rolling down a hillslope without relying on any anchorage to its support. A range of geometric design of the barriers with L-shaped cross sections also have been considered and analysed. The new approach presented in this paper is easy to apply in practice and will be useful for engineers designing concrete barriers as passive rockfall mitigation measures.
\end{abstract}

Keywords: rockfall, impact action, L-shaped rigid barrier, displacement-based approach, overturning stability 


\section{Notation}

$l \quad=\quad$ length of base slab

$c \quad=\quad$ length of side wall

$\mathrm{COR}=\quad$ coefficient of restitution

$d \quad=\quad$ height of side wall

$g=$ gravitational acceleration

$h \quad=\quad$ height of barrier

$h_{\mathrm{i}}=\quad$ vertical distance between point of impact and the axis of rotation

$I_{\theta} \quad=\quad$ rotational inertia

$\mathrm{KE}_{0}=\quad$ initial kinetic energy of boulder

$\mathrm{KE}_{1}=$ rebound kinetic energy of boulder

$\mathrm{KE}_{2}=\quad$ kinetic energy gained by the barrier

$M \quad=\quad$ total mass of barrier

$M_{\text {base }}=\quad$ mass of barrier base slab

$M_{\text {side }}=\quad$ mass of a single side wall

$M_{\text {stem }}=\quad$ mass of stem wall

$M_{\mathrm{o}} \quad=\quad$ overturning moment

$M_{\mathrm{o}} \quad=\quad$ restoring moment

$m \quad$ = mass of boulder

$n=$ number of side walls

$\mathrm{PE} \quad=\quad$ potential energy gained by the barrier due to rotation

$R=$ distance between the axis of rotation and the point of impact

$r_{\text {base }}=$ distance between the axis of rotation and the centroidal axis of the base slab

$r_{\text {side }}=$ distance between the axis of rotation and the centroidal axis of the side wall

$r_{\text {stem }}=$ distance between the axis of rotation and the centroidal axis of the stem wall 


$$
\begin{aligned}
& v_{0}=\quad \text { initial velocity of boulder } \\
& v_{1}=\text { rebound velocity of boulder } \\
& v_{2}=\quad \text { velocity of barrier at the point of impact } \\
& w_{\text {base }}=\quad \text { width of base slab } \\
& w_{\text {side }} \quad=\quad \text { width of side wall } \\
& w_{\text {stem }}=\quad \text { width of stem wall } \\
& \bar{x}=\text { horizontal distance to the barrier's centre of gravity from global vertical axis } \\
& \bar{y} \quad=\quad \text { vertical distance to the barrier's centre of gravity from global horizontal axis } \\
& z \quad=\quad \text { global axis (axis of rotation) } \\
& z_{\mathrm{c}} \quad=\quad \text { centroidal axis } \\
& \Delta=\text { horizontal displacement of barrier } \\
& \Delta_{\text {C.G. }}=\text { rise in the centre of gravity of barrier } \\
& \Delta_{\text {C.G.(crit) }}=\quad \text { rise of the barrier's centre of gravity at the critical overturning condition } \\
& \kappa \quad=\quad \text { a dimensionless ratio considering mass and geometrical effects } \\
& \theta=\text { angle of rotation } \\
& \theta_{\text {crit }}=\text { critical angle of rotation } \\
& \dot{\theta}=\text { angular velocity }
\end{aligned}
$$




\section{INTRODUCTION}

Reinforced concrete barriers are commonly used as passive defence measures to protect buildings and infrastructures from natural hazards such landslides and rockfalls (e.g. Paronuzzi 1989; Patnaik et al. 2015; Ng et al. 2016). To perform their intended functions, these structures should be capable of withstanding the impact force of the falling debris. Currently they are typically designed using a force-based approach where the conditions of force and moment equilibrium are satisfied with a certain factor of safety. For example, Fig. 1 shows an L-shaped barrier with stiffening counterforts constructed on a natural hillslope in Hong Kong. This barrier was designed to resist the impact of a 1.8 -m diameter boulder travelling at a velocity of $15 \mathrm{~m} / \mathrm{s}$. The equivalent impact force was estimated using the simplified Hertz equation given in Kwan (2012), and the barrier was designed to have sufficient weight to counterbalance the impact force and the induced overturning moment.

The use of a force-based approach for analysing dynamic impact problems may lead to overconservative design since certain important phenomena such as the effect of inertial resistance and the actual amount of energy transferred to the structure are neglected. Despite these limitations, at present there is very limited guidance in the literature on how to deal with complex interactions between an impactor and an impact-resisting structure. Civil engineers working on the design of impact-resisting structures, such as bridge piers and vehicle parapets, commonly adopt the conventional approach of treating the impact action as equivalent static forces as stipulated by the relevant design guidelines (e.g. CEN 2006; Kim et al. 2012; AASHTO 2014). The use of this forced-based approach could result in over-conservative design because the duration of an impact force typically lasts for only a small fraction of a second as opposed to a continuing pseudo-static force which is implied in a conventional analysis. Calculation methods based on the assumption of equal energy (i.e. no energy loss) could also result in grossly erroneous estimates of impact forces if only a fraction of energy delivered by the impactor is absorbed by the structure. It should be noted that calculation procedures based on measured or 
simulated contact force could still give misleading results if the time dimension, and/or inertial resistance generated from the resisting structures have not been fully factored into the calculation. Recent research has shown that, although the contact force may cause localised damage, only a small fraction of the force is actually transmitted to the rest of the structure due to its inertial resistance (Ali et al. 2014; Sun et al. 2014). Therefore, the contact force generated by an impact could be an order of magnitude higher than the reaction force that the foundation need be designed to resist.

To overcome the shortcomings of the existing design approaches, this paper presents a novel approach for the assessment of overturning stability of L-shaped reinforced concrete barriers, with and without side walls or stiffening counterforts. This approach which is based on the principles of energy and momentum conservation considers the inertial resistance of the barrier and energy lost on impact. Stability is assessed by comparing the calculated movement with the critical value for the barrier. In this paper, derivations of the analytical solutions are first presented. Results obtained from laboratory impact experiments are then used to verify the accuracy of the solutions. The results of a parametric study are then presented to highlight the effect of barrier geometry on overturning stability. Limitations of the new method will also be discussed.

\section{ANALYTICAL SOLUTIONS}

\section{Barrier geometry}

Fig. 2 shows an L-shaped barrier with its height and slab length of the barrier denoted as $h$ and $l$ respectively. The stem wall of the barrier is impacted by a single boulder with mass $m$ and travelling at an initial velocity $v_{0}$, which is defined as the velocity immediately before the impact. The boulder hits the stem wall at a distance $h_{\mathrm{b}}$ above the point of rotation. Immediately following the impact, the barrier gains kinetic energy $\left(\mathrm{KE}_{2}\right)$ which is then converted to potential energy (PE) as the barrier rotates (similar to the case of a swinging pendulum). The barrier's centre of gravity 6 
also rises by the vertical distance $\Delta_{\text {C.G. }}$. The angle of rotation is denoted as $\theta$ and the top of the barrier travels a horizontal distance $\Delta$. The thicknesses of the stem wall and the base slab are $w_{\text {stem }}$ and $w_{\text {base }}$ respectively.

\section{Reference case: no energy loss}

If there is no energy loss, the maximum value of $\Delta_{\text {C.G. }}$ can be obtained readily by equating the boulder's initial kinetic energy $\left(\mathrm{KE}_{0}=0.5 m v_{0}^{2}\right)$ with the barrier's gain in potential energy $\left(\mathrm{PE}=M g \Delta_{\mathrm{C} . \mathrm{G} .}\right)$ to obtain the following equation:

$$
\Delta_{\text {C.G. }}=\frac{m v_{0}^{2}}{2 M g}
$$

where $M$ is the total mass of the barrier and $g$ is gravity. A major shortcoming of Equation 1 is that the amount of kinetic energy delivered by the boulder is assumed to be equal to the amount of potential energy gained by the barrier, and that no consideration is given to the geometry of the barrier. In reality, only a fraction of the energy is transferred to the barrier, with the rest of the energy being partly carried away by the rebounding boulder and partly dissipated in the form of heat and sound. The implication of energy partitioning between the impactor and the target (barrier) for impact problems has been discussed previously by Ali et al. (2014) and Lam et al. (2018). To take into account the effects of energy loss and the inertial resistance of the barrier, the principles of momentum and energy conservation can be incorporated into the derivation following the approach developed by Lam et al. (2018) for calculating the movement of rectangular blocks subjected to point-load impacts, as follows. 


\section{Consideration of momentum conservation}

The angular momentum of a barrier is the product of its rotational inertia $\left(I_{\theta}\right)$ and angular

velocity $(\dot{\theta})$. By considering the conservation of angular momentum for the case shown in Fig. 2, the following equation can be written:

$m v_{0} h_{\mathrm{i}}=I_{\theta} \dot{\theta}-m v_{1} h_{\mathrm{i}}$

where $v_{0}$ and $v_{1}$ are the initial and rebound velocities of the boulder respectively, and $h_{\mathrm{i}}$ is the perpendicular distance between the bottom of the base slab and the boulder.

\section{Rotational inertia (mass moment of inertia)}

For an L-shaped barrier, $I_{\theta}$ can be approximated as:

$I_{\theta} \approx \frac{M_{\text {stem }}}{3}\left(h^{2}+h w_{\text {base }}\right)+\frac{M_{\text {base }} b^{2}}{3}$

where $M_{\text {stem }}$ and $M_{\text {base }}$ denote the masses of the stem wall and the base slab respectively. For Lshaped barriers with rectangular side walls, Equation 3 can be expanded to become:

$I_{\theta} \approx \frac{M_{\text {stem }}}{3}\left(h^{2}+h w_{\text {base }}\right)+\frac{M_{\text {base }} b^{2}}{3}+n M_{\text {side }}\left[\left(\frac{c^{2}+d^{2}}{12}\right)+\left(\frac{d}{2}+w_{\text {stem }}\right)^{2}+\left(\frac{c}{2}+w_{\text {stem }}\right)^{2}\right]$

where $n$ and $M_{\text {side }}$ are the number and the mass of side walls respectively; $c$ and $d$ denote the length and height of the side walls respectively. Derivations of Equations 3 and 4 are given in Appendix A. 


\section{Consideration of velocity}

By considering the geometry of the barrier, it can be shown that the angular velocity $\dot{\theta}$ of the barrier can be expressed as:

$\dot{\theta}=\frac{\mathrm{d} \theta}{\mathrm{d} t}=\frac{v_{2}}{R}$

where $v_{2}$ is the velocity of the barrier at the point of impact, and $R$ is the distance between the point of rotation and the impact location. It can be shown that for the barrier shown in Fig. $2, R$ equals $\sqrt{h_{\mathrm{i}}^{2}+w_{\text {stem }}^{2}}$. Substituting Equation 5 into Equation 2 and rearranging gives:

$v_{0}+v_{1}=\left(\frac{I_{\theta}}{m h_{1} R}\right) v_{2}$

Let $\kappa=\frac{I_{\theta}}{m h_{\mathrm{i}} R}$ (dimensionless), Equation 6 now becomes:

$v_{0}+v_{1}=\kappa v_{2}$

Adding $v_{2}$ to both sides of the equation and then dividing by $v_{0}$ gives:

$1+\frac{v_{1}+v_{2}}{v_{0}}=(1+\kappa) \frac{v_{2}}{v_{0}}$

At this point, it is useful to introduce the coefficient of restitution (COR) which is a measure of kinetic energy loss during an impact (collision). When the COR is 0 , the impact is termed "inelastic" and the two objects coalesce and travel together after the impact. When the COR is 1 , 
kinetic energy is conserved and the impact is termed "elastic". In this case, the objects rebound from each other with the same relative speed but in opposite directions. When the COR is between 0 and 1, the impact is termed "partially elastic" and some of the kinetic energy is converted to other forms of energy such as heat, sound and work done deforming the object. The COR is commonly defined as the ratio of relative speeds immediately after and before the impact, i.e., $\operatorname{COR}=\left(v_{1}+v_{2}\right) / v_{0}$. Substituting this definition into Equation 8 and rearranging gives:

$$
\frac{v_{2}}{v_{0}}=\frac{1+\mathrm{COR}}{1+\kappa}
$$

Equation 9 is particularly useful because it relates the rebound-to-initial velocity ratio of the impacting boulder to the COR and the dimensionless ratio $\kappa$, both of which can be determined for a particular impact scenario. The value of the COR of an impact between the boulder and the barrier can be estimated with reference to previous research such as Chau et al. (1998) and Wyllie (2015), whereas factor $\kappa$ can be calculated using the size and dimensions of the barrier and the boulder.

\section{Consideration of rotational kinetic energy}

Now consider the rotational kinetic energy of the barrier:

$\mathrm{KE}_{2}=\frac{1}{2} I_{\theta} \dot{\theta}^{2}$

Substituting Equation 5 into Equation 10 and again letting $\kappa=\frac{I_{\theta}}{m h_{\mathrm{i}} R}$ gives:

$\mathrm{KE}_{2}=\frac{1}{2} I_{\theta}\left(\frac{v_{2}}{R}\right)^{2}=\frac{1}{2}\left(\frac{I_{\theta}}{m h_{\mathrm{i}} R}\right) \frac{v_{2}^{2} m h_{\mathrm{i}}}{R}=\frac{1}{2} \times \frac{\kappa v_{2}^{2} m h_{\mathrm{i}}}{R}$ 
With Equation 9, the ratio of energy transfer from the boulder to the barrier, i.e., the energyreduction ratio, can be expressed and manipulated as follows:

$\frac{\mathrm{KE}_{2}}{\mathrm{KE}_{0}}=\frac{\frac{1}{2} \times \frac{\kappa v_{2}^{2} m h_{1}}{R}}{\frac{1}{2} m v_{0}^{2}}=\frac{\kappa h_{1}}{R}\left(\frac{v_{2}}{v_{0}}\right)^{2}=\frac{\kappa h_{1}}{R}\left(\frac{1+\mathrm{COR}}{1+\kappa}\right)^{2}$

Rearranging Equation 12 finally leads to:

$\mathrm{KE}_{2}=\frac{1}{2} m v_{0}^{2} \times \frac{\kappa h_{\mathrm{i}}}{R}\left(\frac{1+\mathrm{COR}}{1+\kappa}\right)^{2}$

Equations 12 and 13 show that the amount of energy transferred to the barrier does not equal the kinetic energy of the impacting boulder $\left(\mathrm{KE}_{0}\right)$, but is a function of the barrier's geometrical properties and the coefficient of restitution between the two objects. These effects are taken into account by the additional term $\frac{\kappa h_{\mathrm{i}}}{R}\left(\frac{1+\mathrm{COR}}{1+\kappa}\right)^{2}$.

\section{Consideration of energy conservation}

By conservation of energy, the barrier's gain in kinetic energy $\left(\mathrm{KE}_{2}\right)$ is gradually converted to potential energy $\left(\mathrm{PE}=M g \Delta_{\mathrm{C} . \mathrm{G}}\right)$ as the barrier rotates. Therefore, the maximum rise of the barrier's centre of gravity $\left(\Delta_{\text {C.G. }}\right)$ can be expressed as:

$\Delta_{\text {C.G. }}=\frac{m v_{0}^{2}}{2 M g} \times \frac{\kappa h_{1}}{R}\left(\frac{1+\mathrm{COR}}{1+\kappa}\right)^{2}$ 
By comparing Equation 1 with Equation 14, again it can be seen that the effects of inertial resistance and energy loss are taken into account by the additional term $\frac{\kappa h_{\mathrm{i}}}{R}\left(\frac{1+\mathrm{COR}}{1+\kappa}\right)^{2}$, which is the energy-transfer ratio (Equation 12). From geometry, it can be shown that the angle of rotation $\theta$ is related to $\Delta_{\text {C.G. }}$ via the following equation:

$$
\theta=\sin ^{-1}\left[\frac{\bar{y}+\Delta_{\mathrm{C} . \mathrm{G} .}}{\sqrt{\bar{x}^{2}+\bar{y}^{2}}}\right]-\tan ^{-1}\left(\frac{\bar{y}}{\bar{x}}\right)
$$

where $\bar{x}$ and $\bar{y}$ are the distances to the barrier's centre of gravity measured from the outer edge of the stem wall (global vertical axis) and the base slab (global horizontal axis) respectively.

\section{Critical overturning condition}

In assessing the stability of a barrier, the calculated $\Delta_{\text {C.G. }}$ (Equation 14 ) can be compared with the

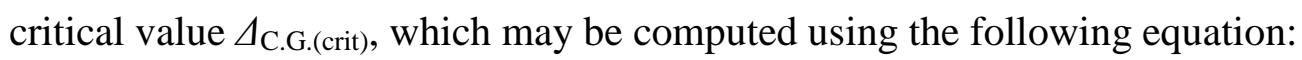

$$
\Delta_{\text {C.G.(crit) }}=\sqrt{\bar{x}^{2}+\bar{y}^{2}}-\bar{y}
$$

Similarly, the calculated $\theta$ (Equation 15) can be compared with the critical value which has the following form:

$\theta_{\text {crit }}=90^{\circ}-\tan ^{-1}\left(\frac{\bar{y}}{\bar{x}}\right)$

The derivations of Equations 16 and 17 are given in Appendix B. 


\section{EXPERIMENTAL VERIFICATION}

In order to verify the displacement-based analytical solutions derived in the previous section, pendulum impact tests of laboratory-scale were carried out on a free standing L-shaped concrete block. The concrete block had a density of $2400 \mathrm{~kg} / \mathrm{m}^{3}$ and dimensions of $0.8 \mathrm{~m} \times 0.6 \mathrm{~m} \times 0.4 \mathrm{~m}$ $(h \times l \times b)$. The widths of the stem wall $\left(w_{\text {stem }}\right)$ and of the base slab $\left(w_{\text {base }}\right)$ were both $0.2 \mathrm{~m}$. The dimensions are shown in Fig. 3(a). A photograph of the experimental setup is shown in Fig. 3(b). A spherical cast iron object with mass of $5 \mathrm{~kg}$ was used as the impactor which was connected with two steel cables to guide its motion, and was raised to heights of $0.5 \mathrm{~m}, 1.0 \mathrm{~m}$ and $1.5 \mathrm{~m}$ before it was released to strike the concrete block. The impact velocities corresponding to these heights were $3.13 \mathrm{~m} / \mathrm{s}, 4.43 \mathrm{~m} / \mathrm{s}$ and $5.42 \mathrm{~m} / \mathrm{s}$ respectively. A steel plate weighing about 1 $\mathrm{kg}$ was placed in between the impactor and the concrete block to prevent accumulative localised damage to the concrete surface following multiple strikes. As the mass of the steel plate was insignificant compared to concrete, its only effect on the experimental results was the COR values, which were captured and measured with the use of a high-speed camera.

The rise in the centre of gravity $\Delta_{\text {C.G. }}$ could not be measured directly from the experiment. The horizontal displacement at the top of the wall $(\Delta)$ was measured instead. To this end, a laser displacement transducer with a measurement frequency of $1.5 \mathrm{kHz}$ and a measurement range of $600 \mathrm{~mm}$ was placed behind the concrete block. The peak horizontal displacement measured from each test could then be compared with that calculated from the analytical solutions. The theoretical horizontal displacement $\Delta$ was obtained by first calculating the angle of rotation $(\theta)$ using Equation 15 and the converting it to $\Delta$ using the following equation:

$\Delta=h \sin \theta$

Fig. 4 shows the measured and computed results. The COR values were measured to be 0.502 , 0.454 and 0.363 for impactor release height of $0.5 \mathrm{~m}, 1.0 \mathrm{~m}$ and $1.5 \mathrm{~m}$ respectively. Details of the 13 
calculations are not given here as they will be illustrated in a worked example in the next section. As can be seen, there are good consistencies between the measured and theoretical results for the three impact tests. The accuracy of the analytical solutions is thus verified.

\section{NUMERICAL ASSESSMENT}

\section{Worked example}

A worked example is presented herein to illustrate the use of the analytical solutions in practice. To show the advantage of the new design approach, the result is also compared with that obtained from the conventional approach which is based on moment equilibrium. The barrier considered had a height $(h)$ of $3 \mathrm{~m}$, a slab length $(l)$ of $6 \mathrm{~m}$ and a width $(b)$ of $10 \mathrm{~m}$. The widths of the stem wall $\left(w_{\text {stem }}\right)$ and of the base slab $\left(w_{\text {base }}\right)$ were both $1 \mathrm{~m}$. A boulder with a diameter of $1.8 \mathrm{~m}$ $(\phi)$ and an initial velocity $\left(v_{0}\right)$ of $15 \mathrm{~m} / \mathrm{s}$ is assumed to impact on the top of the stem wall (i.e., $\left.h_{i}=h\right)$. These values were taken from the real-life example shown in Fig. 1, and the assumed impact location represents the worst-case scenario in terms of the barrier's overturning stability. The coefficient of restitution (COR) is conservatively taken as 0.5 after a review of the relevant literature (e.g. Chau et al. 1998; Wyllie 2015). It should be noted that the COR is a function of material properties and impact velocity (Jankowski 2010; Sun et al. 2015; Perera et al. 2016), so its value will need to be considered on a case-by-case basis. If the density of reinforced concrete $\left(\rho_{\mathrm{c}}\right)$ was taken as $2,500 \mathrm{~kg} / \mathrm{m}^{3}$, the stem wall $\left(M_{\text {stem }}\right)$ and the base slab $\left(M_{\text {slab }}\right)$ of the barrier will weigh $50,000 \mathrm{~kg}$ and $150,000 \mathrm{~kg}$ respectively, thus giving a total mass $(M)$ of $200,000 \mathrm{~kg}$. The mass of the boulder $(m)$ would be $8,092 \mathrm{~kg}$ if its density was $2,650 \mathrm{~kg} / \mathrm{m}^{3}$. Using the analytical solutions presented previously, the following parameters can be determined:

Distance between axis of rotation and impact location: $R=3.1623 \mathrm{~m}$

Rotational inertia: $I_{\theta} \approx 2,000,000 \mathrm{~kg} \cdot \mathrm{m}^{2}$

Dimensionless number: $\kappa=26.0523$ 
Therefore, the maximum rise in the barrier's centre of gravity was:

$$
\Delta_{\text {C.G. }}=\frac{m v_{0}^{2}}{2 M g} \times \frac{\kappa h_{1}}{R}\left(\frac{1+\mathrm{COR}}{1+\kappa}\right)^{2}=\frac{8092 \times 15^{2}}{2 \times 200,000 \times 9.81} \times \frac{26.0523 \times 3}{3.1623} \times\left(\frac{1+0.5}{1+26.0523}\right)^{2}=0.0353 \mathrm{~m}
$$

The overturning stability of the barrier could be assessed by comparing the calculated $\Delta_{\text {C.G. }}$ with the critical value $\Delta_{\text {C.G.(crit). }}$ To this end, the centre of gravity of the barrier needs to be located with reference to a global origin, which could be set conveniently at the point of rotation. For objects with a uniform density, the centre of gravity is the same as the geometrical centre. For the barrier considered in this example, the centre of gravity was located at $\bar{x}=2.375 \mathrm{~m}$ and $\bar{y}=$ $0.875 \mathrm{~m}$. Therefore $\Delta_{\text {C.G.(crit) }}=\sqrt{\bar{x}^{2}+\bar{y}^{2}}-\bar{y}=1.6561 \mathrm{~m}$. If the factor of safety (FOS) against overturning was defined as $\Delta_{\text {C.G.(crit) }} / \Delta_{\text {C.G. }}$, then this barrier would have a FOS of 47 . This result indicates that the barrier has sufficient capacity against overturning despite its temporary rotational movement.

On the other hand, if this same barrier was assessed using the conventional force-based approach, the impact force would be $8353 \mathrm{kN}$ which could be calculated using the simplified Hertz equation (Kwan, 2012). This force would induce an overturning moment $\left(M_{\mathrm{o}}\right)$ of $25,060 \mathrm{kNm}$ $(=8353 \mathrm{kN} \times 3 \mathrm{~m})$ on the barrier. Since the total weight of the barrier was $1962 \mathrm{kN}$ (barrier mass equals $200,000 \mathrm{~kg}$ ) and the centre of gravity was at a horizontal distance of $2.375 \mathrm{~m}$ from the axis of rotation, the restoring moment $\left(M_{\mathrm{r}}\right)$ would be $4660 \mathrm{kNm}(=1962 \mathrm{kN} \times 2.375 \mathrm{~m})$. If the FOS was defined in the conventional manner as $M_{\mathrm{r}} / M_{\mathrm{o}}$, this barrier would have a FOS of merely 0.19 , which would in fact be not surprising given that the barrier was expected to rock slightly following the impact. 
If the barrier is assumed to be simultaneously impacted by two boulders instead of one, the same calculation procedure can be adopted. Parameter $m$ may represent the combined mass of the impacting boulders and is $16,184 \mathrm{~kg}(=8092 \mathrm{~kg} \times 2)$. The value of the dimensionless ratio $\kappa$, which is a function of $m$, is reduced to 13 which is about half of the original value. If all other conditions remain the same, the maximum rise in the barrier's centre of gravity $\left(\Delta_{\text {C.G. }}\right)$ becomes $0.13 \mathrm{~m}$ and the corresponding value of the FOS is 12.6 .

It is noted the barrier analysed in the above worked example has a high safety margin in terms of overturning even when subjected to simultaneous impact by two sizeable boulders. Thus, the original design can be optimised by reducing the dimensions of the stem wall and the base slab, provided that the wall has sufficient structural strength to resist the predicted impact. The key to a successful design is to limit the barrier's movement to an acceptable level. This topic will be explored in the following section.

\section{Parametric study}

A parametric study has been carried out using the analytical solutions to investigate the effect of the change in geometry on the overturning stability of the barrier. The same barrier considered in the previous example was used for this study, except that the length of the barrier varied from 1 to $10 \mathrm{~m}$. The length-to-height ratio $(l / h)$ of the barrier thus varied from 0.33 to 3.33 . The weight and the rotational inertia of the barrier would also vary. To assess the effect of these changes, Fig. 5 plots the energy-transfer ratio $\left(\mathrm{KE}_{2} / \mathrm{KE}_{0}\right)$ against $l / h$. It can be seen that the value of $\mathrm{KE}_{2} / \mathrm{KE}_{0}$ drops rapidly when the value of $l / h$ increases from 0.33 to around 2.0 , which is true for all COR values. When the value of $l / h$ increases further, the rate of reduction becomes increasingly smaller. Results show that for a given wall height, increasing the slab length will be more effective for barriers with low $l / h$ values. For any length-to-height ratio, a reduction in the $\mathrm{COR}$ would also lead to a reduction in $\mathrm{KE}_{2} / \mathrm{KE}_{0}$ (Fig. 5). Recalling that $\mathrm{COR}$ is a measure of 
the amount of kinetic energy loss in the course of the impact. For impact with a low value of COR, a large amount of kinetic energy is lost and less energy is therefore transferred to the barrier. It can be shown that the effects of COR gradually diminish when the value of $l / h$ increases. This is because when $l / h$ is high, the inertial resistance of the barrier becomes the controlling factor in energy partitioning. Lastly, it can be seen that even for an elastic collision where there is no loss of kinetic energy $(\mathrm{COR}=1)$, the value of $\mathrm{KE}_{2} / \mathrm{KE}_{0}$ is still less than 1 because of the inertial resistance of the barrier being larger than that of the impacting boulder.

Fig. 6 shows the rise in the barrier's centre of gravity $\left(\Delta_{\text {C.G. }}\right)$ against $l / h$. To allow an evaluation of the barrier's overturning stability, curves corresponding to FOS of 1, 10 and 50 are also shown for reference. Two observations can be made from this plot. First, the shape of the computed $\Delta_{\text {C.G. }}$ curves much resemble those for $\mathrm{KE}_{2} / \mathrm{KE}_{0}$, except that the initial portion of the curves with low $l / h$ values is not available because the barrier is predicted to have overturned. This resemblance is actually expected because the value of $\Delta_{\text {C.G. }}$ is directly proportional to that of the energy-reduction term according to Equation 14. Second, a high FOS appears to be appropriate if the movement of the barrier is limited to, say, below $50 \mathrm{~mm}$. The amount of "acceptable" movement should depend on a number of factors, such as the site setting and the structural design of the barrier. Lastly, it is emphasised that Fig. 5 and 6 are only valid for the impact scenario assumed in this exercise. Similar graphs can be produced using spreadsheet to assist in the sizing of the barrier for a different impact scenario.

\section{LIMITATIONS}

The limitations of the analytical solutions are discussed in this section. First, the solutions were derived assuming that the boulder would rebound from the barrier following the impact. In other words, the solutions are valid for elastic or partially elastic impact $(0<\mathrm{COR} \leq 1)$, but not for inelastic impact ( $\mathrm{COR}=0$ ). This assumption should be valid for most situations except for the 
case where the boulder becomes embedded into the barrier, which is a situation that can be avoided by adequate structural design. Another possible situation where rebounce may not occur is when the barrier is shielded by a granular cushion layer such as rock-filled gabions (Bourrier et al. 2008; Kwan et al. 2016; Ng, et al. 2016). In this case, the cushion layer will dissipate the impact energy through elasto-plastic deformation. Further research will be required to develop and validate analytical solutions for these impact scenarios.

The second limitation is that the barrier under impact needs to be structurally robust to behave as a 'rigid' body. If the stem wall is only lightly reinforced, punching failure may occur around the impact location. This situation can be avoided by performing checks against punching failure. Calculation methods are available for this purpose (e.g. CEB, 1988; Micallef et al. 2014). Another possibility is that if the wall-slab connection is not sufficiently rigid, the barrier wall may behave as a cantilever. Yielding may occur near the base where bending moment is maximum. To design wall against bending failure, the simplified Hertz equation given in Kwan (2012) or the analytical solutions developed by Lam et al. (2018) may be used to estimate the equivalent impact force for use in the structural design. Research is still underway to investigate the structural performance of reinforced concrete barriers when subjected to boulder impact.

The third limitation of the analytical solutions is that the dimensionless ratio $\kappa$ must be greater than 1. Since $\kappa$ is defined as $\frac{I_{\theta}}{m h_{\mathrm{i}} R}$, this ratio takes into account several important factors including the geometrical effect of the barrier, the impact location, and the mass of the impacting boulder. The larger the value of $\kappa$, the greater is the inertial resistance of the barrier. However, if $\kappa$ is smaller than 1 (such as when the barrier is lighter than the impacting boulder), the boulder will not rebound but to continue its trajectory following the impact. Therefore, when sizing a barrier it is necessary to ensure that the barrier is sufficiently robust to resist the predicted impact, which can be achieved by adjusting the value of $I_{\theta}$ so that the value of $\kappa$ is always greater than 1 . 
To put this concept into context, for the barrier considered in the parametric study, the value of $\kappa$ ranges from 2.7 to 111 when the slab length varies from 1 to $10 \mathrm{~m}$. When the value of FOS equals to $10, \kappa$ ranges from 9.5 to 16 depending on the value of the COR. Therefore, the condition of $\kappa>1$ is automatically satisfied for an adequately-sized barrier.

Lastly, it is noted that the calculation methodology presented herein has not included the stabilising action of the soil covering the footing of the L-shaped barrier. Designers have the option to either ignore the additional stabilising action for achieving a conservative design, or to take into account such stabilising action by treating the part of the soil overlying the footing as if it was part of the footing but allowing for the difference in density between the soil and the concrete. For a barrier with a thick layer of overburden soil above the base slab, the dynamic shear resistance at the interface between the moving barrier (including the overburden soil) and the surrounding soil mass can also contribute significantly to the barrier's overturning stability. Further research will be required to take into account such effects in the stability assessment.

\section{CONCLUSIONS}

In this paper, analytical solutions have been presented for the assessment of overturning stability of L-shaped barriers. The solutions are derived based on the principles of momentum and energy conservation, and considerations of the inertial resistance of the barrier and energy loss during the impact. The accuracy of the solutions has been confirmed by laboratory-scale experiments. A worked example has been presented to illustrate the advantage of a displacement-based assessment over the conventional force-based design approach. Both single and multiple boulder impacts have been considered. The conventional design approach has been shown to be overly conservative as compared to the displacement-based approach, and the overestimation is due to the lack of consideration of the inertial resistance of the barrier arising from its own the selfweight and the actual amount of energy transmitted to the structure. A numerical parametric study has also been conducted for an assumed impact scenario. Results show that for a given 
barrier height, the length of the base slab has a profound effect on the energy-transfer ratio and hence the movement of the barrier. This is due to the increase in the inertial resistance of the barrier as its slab length increases. It is hoped that the analytical solutions presented in this paper will be useful for designers of rockfall barriers aiming for a more rational and optimised design. In addition, the solutions may also be adopted for the design of other types of impact-resistant structures such as roadside traffic barriers. 


\section{REFERENCES}

AASHTO (2014). AASHTO LRDF Bridge Design Specifications. $7^{\text {th }}$ Edition, American Association of State Highway and Transportation Officials (AASHTO), Washington, D.C., USA.

Ali, M., Sun, J., Lam, N., Zhang, L. and Gad, E. (2014). Simple hand calculation method for estimating deflection generated by the low velocity impact of a solid object. Australian Journal of Structural Engineering, vol. 15, no. 3, 243-259.

Bourrier, F., Nicot, F. and Darve, F. (2008). Physical processes within a 2D granular layer during an impact. Granular Matter, vol. 10, no. 6, 415-437.

CEB (1988). Concrete Structures under Impact and Impulsive Loading. Bulletin d'Information No. 187, Comité euro-international du béton (CEB), Lausanne.

CEN (2006). Eurocode 1 - Actions on Structures - Part 1-7: General actions - Accidental actions. EN 1991-1-7. Comité Européen de Normalisation (CEN), Brussels.

Chau, K. T., Wong, R. H. C. and Lee, C. F. (1998). Rockfall problems in Hong Kong and some new experimental results for coefficients of restitution. International Journal of Rock Mechanics and Mining Sciences, vol. 35, no. 4-5, 662-663.

Jankowski, R. (2010). Experimental study on earthquake-induced pounding between structural elements made of different building materials. Earthquake Engineering and Structural Dynamics, vol. 39, no. 3, 343-354. 
Kim, K.-M., Briaud, J.-L., Bligh, R. and Abu-Odeh, A. (2012). Design guidelines and full-scale verification for MSE walls with traffic barriers. Journal of Geotechnical and Geoenvironmental Engineering, vol. 138, no. 6, 690-699.

Kwan, J. S. H. (2012). Supplementary Technical Guidance on Design of Rigid Debris-resisting Barriers, GEO Report No. 270, Geotechnical Engineering Office, The Government of the Hong Kong Special Administrative Region, China.

Kwan, J. S. H., Sun, H. W., Lam, C., Koo, R. C. H and Ho, K. K. S. (2016) Recent advances in landslide risk management measures in Hong Kong. Proceedings of the $12^{\text {th }}$ International Symposium on Landslides, Napoli, Italy, pp. 1219-1227.

Lam, N. T. K., Yong, A. C. Y., Lam, C., Kwan, J. S. H., Perera, J. S., Miri Disfani, M. and Gad E. (2018). Displacement-based approach for the assessment of overturning stability of rectangular rigid barriers subjected to point impact. Journal of Engineering Mechanics, vol. 144, no. 2.

Micallef, K., Sagaseta, J., Fernández Ruiz, M., and Muttoni, A. (2014). Assessing punching shear failure in reinforced concrete flat slabs subjected to localised impact loading. International Journal of Impact Engineering, vol. 74, 14-33.

Ng, C. W. W., Choi, C. E., Su, A. Y., Kwan, J. S. H. and Lam, C. (2016) Large-scale successive boulder impacts on a rigid barrier shielded by gabions. Canadian Geotechnical Journal, vol. 53, no. $10,1688-1699$.

Paronuzzi, P. (1989) Probabilistic approach for design optimization of rockfall protective barriers. Quarterly Journal of Engineering Geology, vol. 22, no. 3, 175-183. 
Patnaik, A., Musa, A., Marchetty, S. and Liang, R. (2015) Full-scale testing and performance evaluation of rockfall concrete barriers. Transportation Research Record: Journal of the Transportation Research Board, vol. 2552, 27-36.

Sun, J., Lam, N., Zhang, L., Gad, E., and Ruan, D. (2014). Contact forces generated by fallen debris. Structural Engineering and Mechanics, vol. 50, no. 5, 589-603.

Sun, J., Lam, N., Zhang, L., Ruan, D. and Gad, E. (2015). Contact forces generated by hailstone impact. International Journal of Impact Engineering, vol. 84, 145-158.

Wyllie, D. C. (2015). Rock Fall Engineering. CRC Press, Boca Raton, 270 p. 


\section{APPENDIX A}

\section{Rectangular}

For a rectangular block with height $h$, length $l$ and mass $M$, the rotational inertia about its centroidal axis and its base corner can be respectively expressed as:

$$
\begin{aligned}
& I_{\theta(\text { centroid })}=M\left(\frac{h^{2}+l^{2}}{12}\right) \\
& I_{\theta(\text { base })}=M\left(\frac{h^{2}+l^{2}}{3}\right)
\end{aligned}
$$

\section{L-shaped}

Fig. 7 shows an isometric view of the L-shaped barrier previously shown in Fig. 2. The distances between the global axis $z$ and the centroidal axis of the stem wall $z_{\mathrm{c}(\mathrm{stem})}$ and that of the base slab $z_{\mathrm{c}(\mathrm{base})}$ are $r_{\mathrm{stem}}$ and $r_{\mathrm{base}}$ respectively. The total rotational inertia is the sum of the moments of inertia of the wall $I_{z \text { (stem) }}$ and of the base slab $I_{z \text { (base) }}$. By the parallel axis theorem, the rotational inertia of the stem wall about axis $z$ is:

$$
I_{z(\text { stem })}=I_{z_{\mathrm{c}}(\text { stem })}+M_{\text {stem }} r_{\text {stem }}^{2}
$$

which can be expanded to:

$$
I_{z \text { (stem })}=M_{\text {stem }}\left(\frac{d^{2}+w_{\text {stem }}^{2}}{12}\right)+M_{\text {stem }}\left[\left(\frac{d^{2}}{4}+d w_{\text {base }}+w_{\text {base }}^{2}\right)+\left(\frac{w_{\text {stem }}}{2}\right)^{2}\right]
$$

Since $w_{\text {stem }}$ and $w_{\text {base }}$ are typically much smaller than $d$, ignoring the contributions of their higher-order terms leads to: 


$$
I_{z(\text { stem })} \approx M_{\text {stem }}\left(\frac{d^{2}}{12}\right)+M_{\text {stem }}\left(\frac{d^{2}}{4}+d w_{\text {base }}\right)
$$

Substituting $d=h-w_{\text {base }}$ (see Fig. 7) into Equation A4 and rearranging thus gives:

$$
I_{z(\text { stem })} \approx \frac{M_{\text {stem }}}{3}\left(h-w_{\text {base }}\right)\left(h+2 w_{\text {base }}\right)
$$

According to Equation A2, the rotational inertia of the rectangular base slab about the global axis $z$ can be written as:

$$
I_{z \text { (base })}=\frac{M_{\text {base }}}{3}\left(l^{2}+w_{\text {base }}^{2}\right)
$$

Therefore, the total rotational inertia of the barrier can be obtained by summing Equations A6 and A7:

$$
I_{z} \approx \frac{M_{\text {stem }}}{3}\left(h-w_{\text {base }}\right)\left(h+2 w_{\text {base }}\right)+\frac{M_{\text {base }}}{3}\left(l^{2}+w_{\text {base }}^{2}\right)
$$

Expanding and ignoring the contribution of $w_{\text {base }}^{2}$ leads to:

$$
I_{z} \approx \frac{M_{\text {stem }}}{3}\left(h^{2}+h w_{\text {base }}\right)+\frac{M_{\text {base }} l^{2}}{3}
$$

Equation A8 can be used to estimate the rotational inertia of an L-shaped barrier, but the result will be slightly less than the true value since the higher-order terms of $w_{\text {stem }}$ and $w_{\text {base }}$ have been 25 
neglected. For example, for a barrier with $h$ and $b$ equal to $5 \mathrm{~m}$ and $w_{\text {stem }}$ and $w_{\text {base }}$ equal to $0.5 \mathrm{~m}$, the value of $I_{z_{1} z_{1}}$ is underestimated by $5 \%$ if estimated using Equation A9. This is deemed acceptable for the purpose of routine design since the error is on the safe side. In the main text, $I_{z}$ is written as $I_{\theta}$ to denote that it is the rotational inertia about the axis of rotation.

\section{Rectangular side walls}

Fig. 8 shows an L-shaped barrier with two rectangular side walls. The side walls have height $d$ and length $c$, and the mass of a single side wall is $M_{\text {side }}$. The rotational inertia of a single rectangular side wall about its centroidal axis $z_{\mathrm{c}}$ is:

$$
I_{z_{\mathrm{c}}(\text { side })}=M_{\text {side }}\left(\frac{c^{2}+d^{2}}{12}\right)
$$

where $d=h-w_{\text {base }}$ and $c=l-w_{\text {stem }}$. By the parallel axis theorem, the side wall's rotational inertia about the axis $z$ is:

$$
I_{z(\text { side })}=I_{z_{\mathrm{c}}(\text { side })}+M_{\text {side }} r_{\text {side }}^{2}
$$

where $r_{\text {side }}$ is the distance between axes $z_{\mathrm{c}}$ and $z$, and can be expressed as:

$$
r_{\text {side }}^{2}=\left(\frac{d}{2}+w_{\text {base }}\right)^{2}+\left(\frac{c}{2}+w_{\text {stem }}\right)^{2}
$$

Substituting Equations A10 and A12 into Equation A11 and rearranging gives: 


$$
I_{z(\text { side })}=M_{\text {side }}\left[\left(\frac{c^{2}+d^{2}}{12}\right)+\left(\frac{d}{2}+w_{\text {base }}\right)^{2}+\left(\frac{c}{2}+w_{\text {stem }}\right)^{2}\right]
$$

So far only a single side wall has been considered. For barriers with two identical side walls or more, the combined rotational inertia is therefore:

$$
I_{z \text { (side })}=n M_{\text {side }}\left[\left(\frac{c^{2}+d^{2}}{12}\right)+\left(\frac{d}{2}+w_{\text {base }}\right)^{2}+\left(\frac{c}{2}+w_{\text {stem }}\right)^{2}\right]
$$

where $n$ is the number of side walls. Summing Equations A9 and A14 gives the rotational inertia of the whole barrier:

$$
I_{z} \approx \frac{M_{\text {stem }}}{3}\left(h^{2}+h w_{\text {base }}\right)+\frac{M_{\text {base }}}{3} \times b^{2}+n M_{\text {side }}\left[\left(\frac{c^{2}+d^{2}}{12}\right)+\left(\frac{d}{2}+w_{\text {base }}\right)^{2}+\left(\frac{c}{2}+w_{\text {stem }}\right)^{2}\right]
$$

Equation A15 can be used to calculate the rotational inertia of an L-shaped barrier with any number of rectangular side walls or counterforts about axis $z$, which is the assumed axis of rotation. Equation A15 is only approximate but the error is on the safe side as previously discussed. In the main text, $I_{z}$ is shown as $I_{\theta}$ to denote that it is the rotational inertia about the axis of rotation. 


\section{APPENDIX B}

Fig. 9 shows an L-shaped barrier at the critical overturning condition, that is, when the barrier's centre of gravity lies immediately above its point of rotation. The following derivation is applicable to any shape so long as the barrier's centre of gravity is known. As shown in Fig. 9, the initial centre of gravity is located at the horizontal distance $\bar{x}$ measured from the outer edge of the stem wall and the vertical distance $\bar{y}$ measured from the bottom of the base slab. The distance between the point of rotation and the centre of gravity is thus $\sqrt{\bar{x}^{2}+\bar{y}^{2}}$. At the critical overturning condition, the barrier's angle of rotation and the rise of the centre of gravity are denoted as $\theta_{\text {crit }}$ and $\Delta_{\text {C.G.(crit) }}$ respectively. From geometry, it can be shown that:

$90^{\circ}=\theta_{\text {crit }}+\beta$

Substituting $\beta=\tan ^{-1}\left(\frac{\bar{y}}{\bar{x}}\right)$ and rearranging thus gives:

$\theta_{\text {crit }}=90^{\circ}-\tan ^{-1}\left(\frac{\bar{y}}{\bar{x}}\right)$

The rise of the centre of gravity, $\Delta_{\text {C.G.(crit) }}$, can be expressed as:

$\Delta_{\text {C.G.(crit) }}=\sqrt{\bar{x}^{2}+\bar{y}^{2}}-\bar{y}$ 


\section{List of Figure Captions:}

Fig. 1 An L-shaped rigid rockfall barrier in Hong Kong with stiffening counterforts

Fig. 2 Cross-section of an L-shaped barrier undergoing rotational movement after a rockfall impact

Fig. 3 Experimental setup: (a) Schematic diagram (dimensions in mm), (b) Photograph

Fig. 4 Horizontal displacement of an L-shaped concrete block struck by a pendulum impactor released from different heights

Fig. 5 Energy-transfer ratio for an L-shaped barrier with different length-to-height ratios

Fig. 6 Rise in the centre of gravity for an L-shaped barrier with different length-to-height ratios

Fig. 7 A schematic L-shaped barrier and reference axes

Fig. 8 A schematic L-shaped barrier with rectangular side walls and reference axes

Fig. 9 Cross-section of a schematic L-shaped barrier at critical overturning condition

\section{Graphics programs/tools used:}

Camera: Fig. 1 and Fig. 3(b)

Microstation: Fig. 2, Fig. 7, Fig. 8 and Fig. 9

AutoCAD: Fig. 3(a)

Origin: Fig. 4, Fig. 5 and Fig. 6 


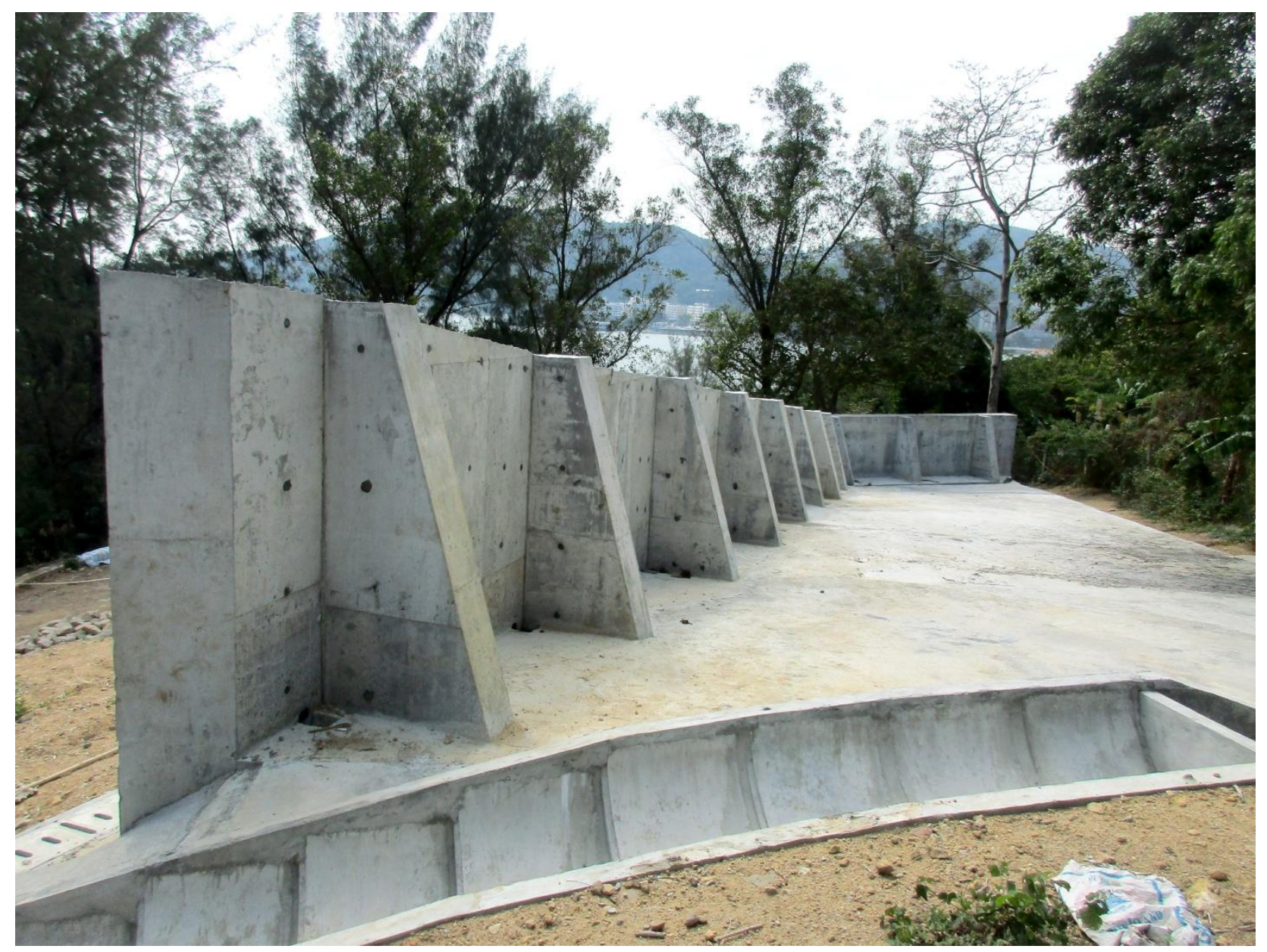




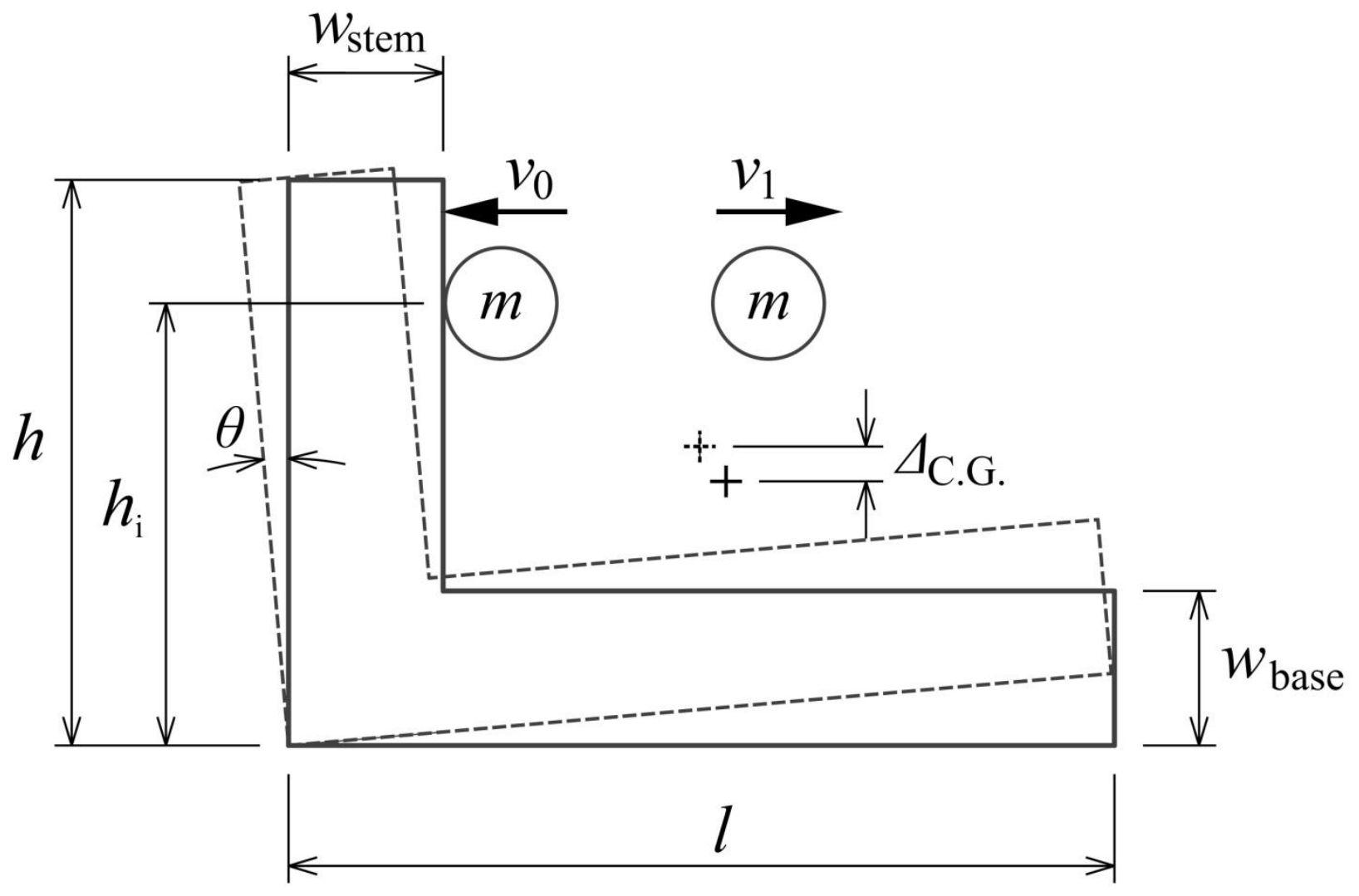









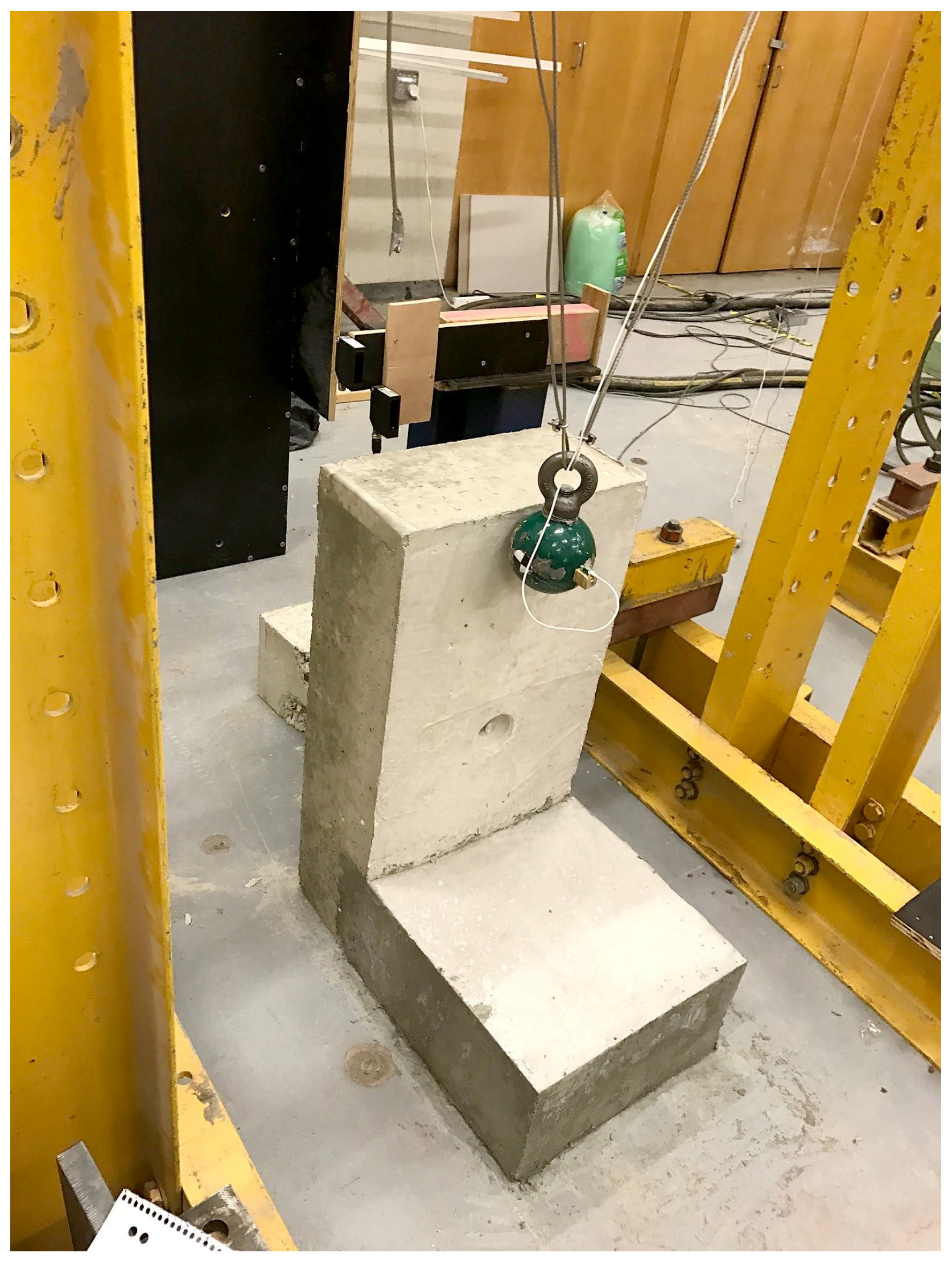




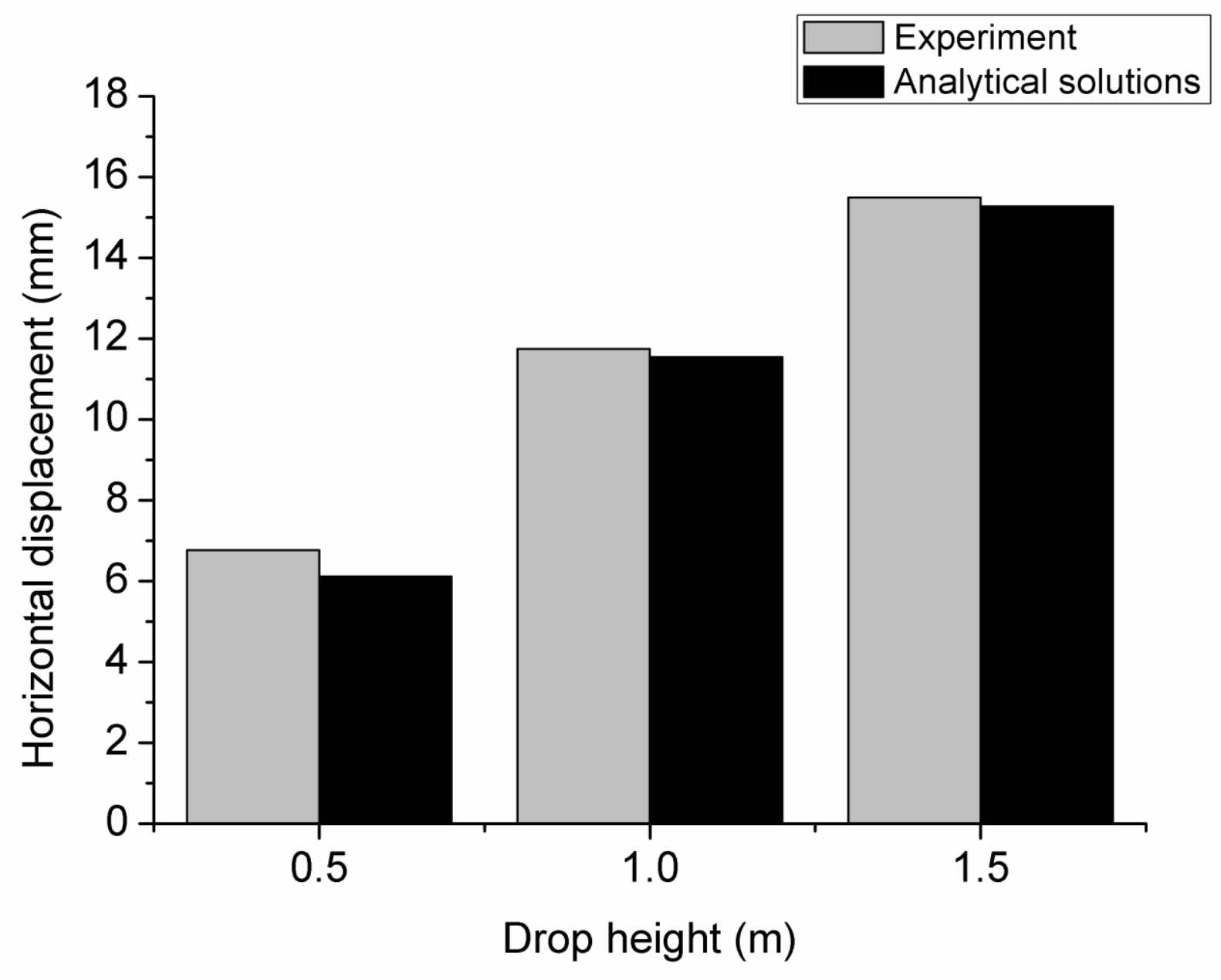




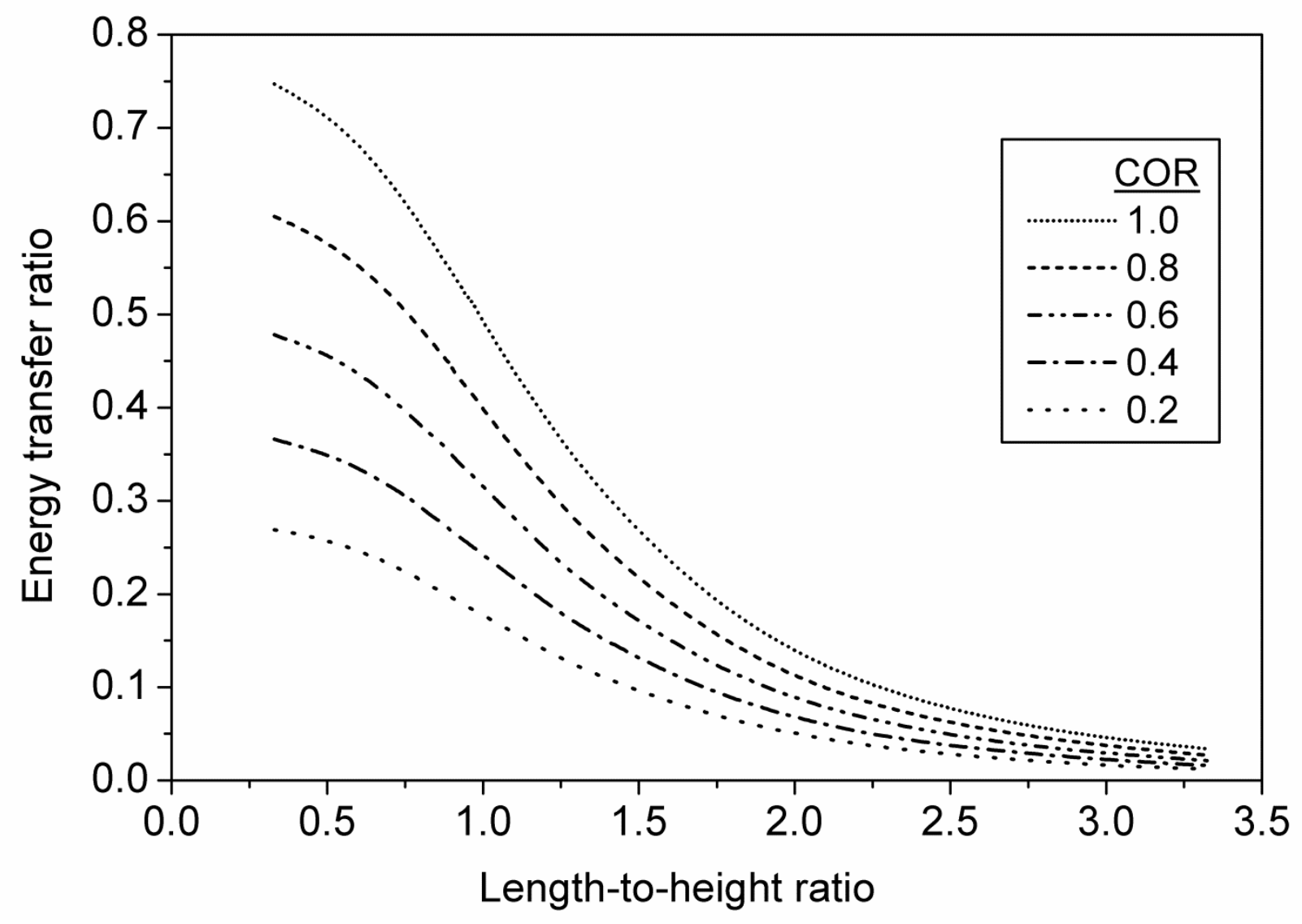




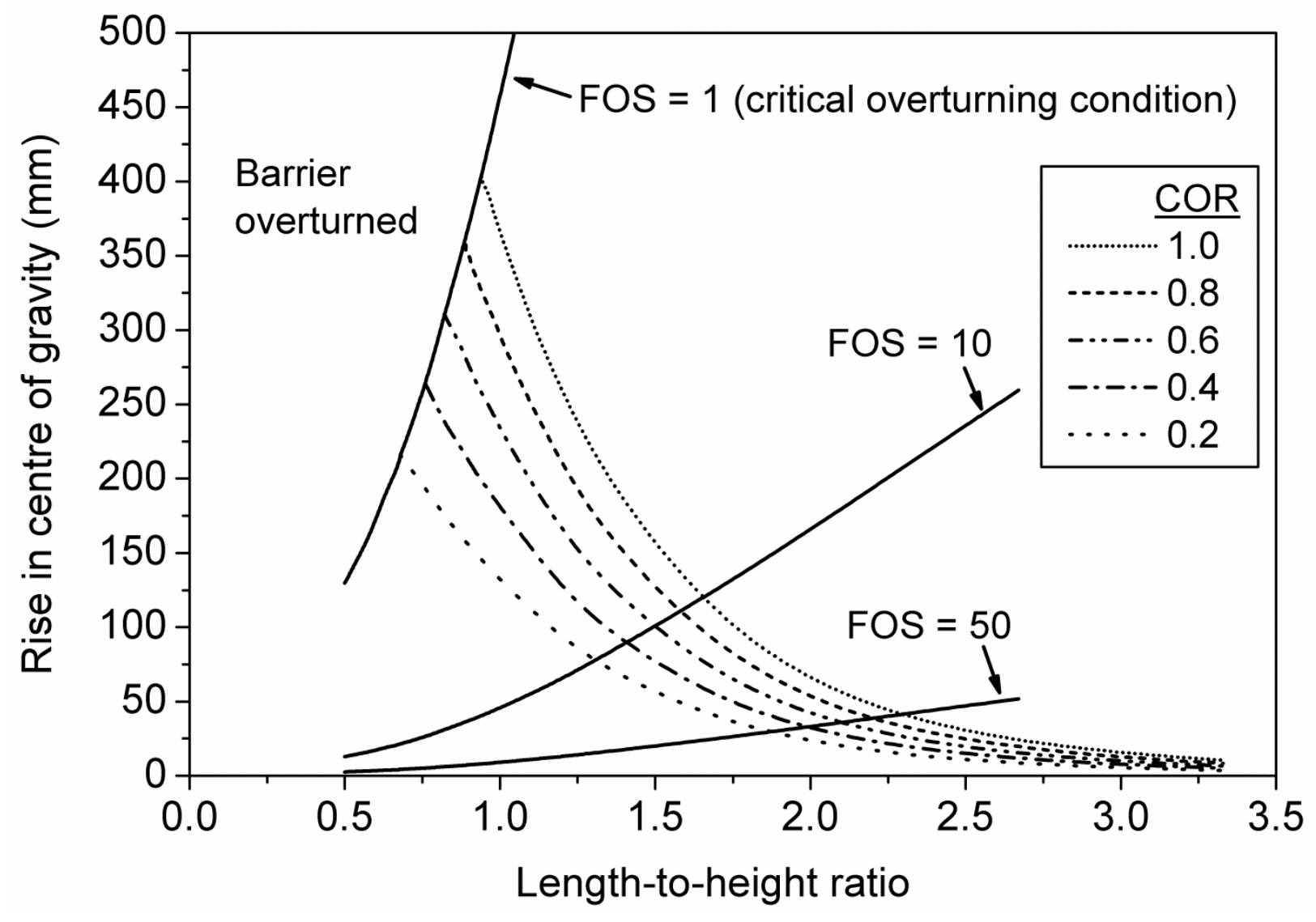




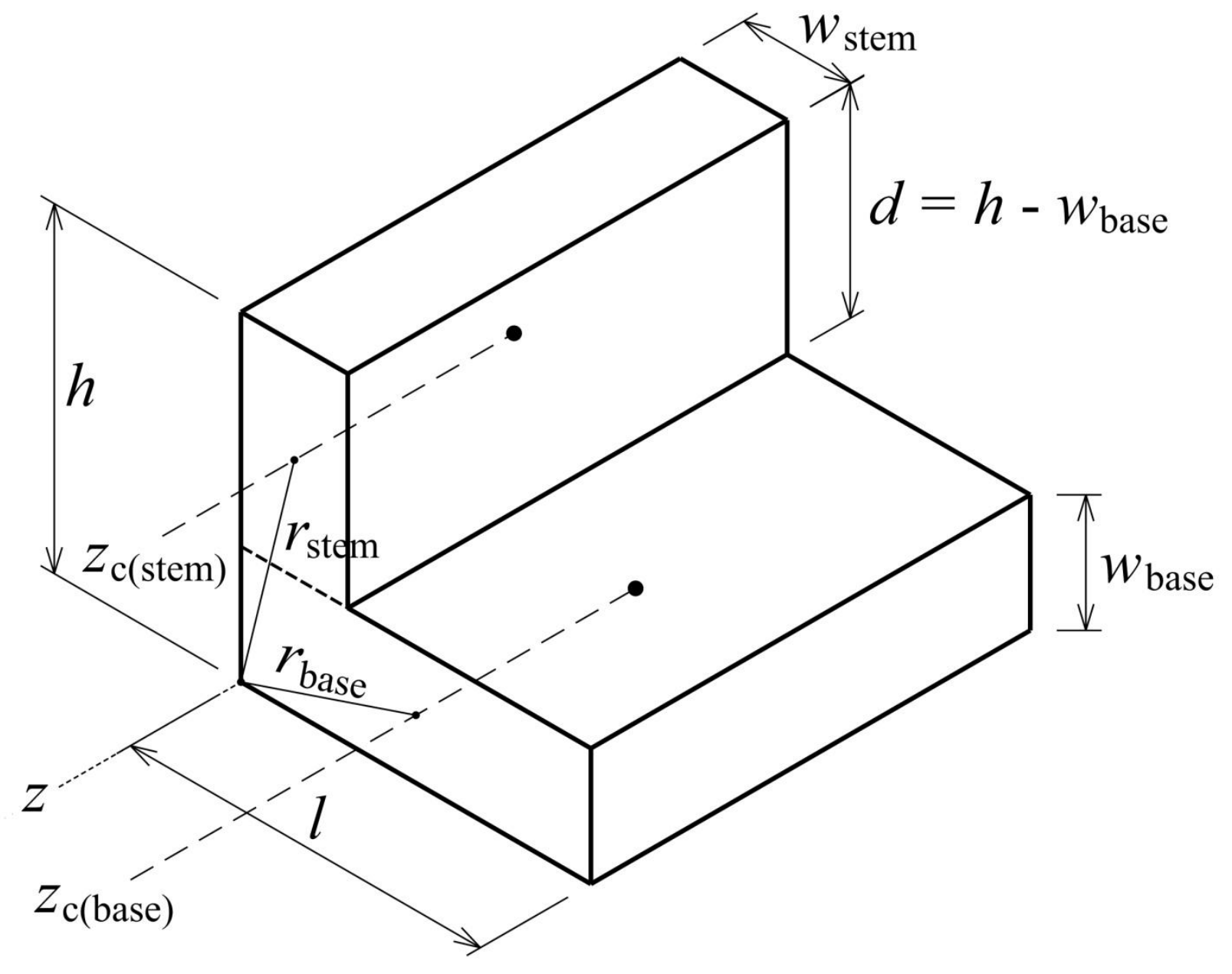




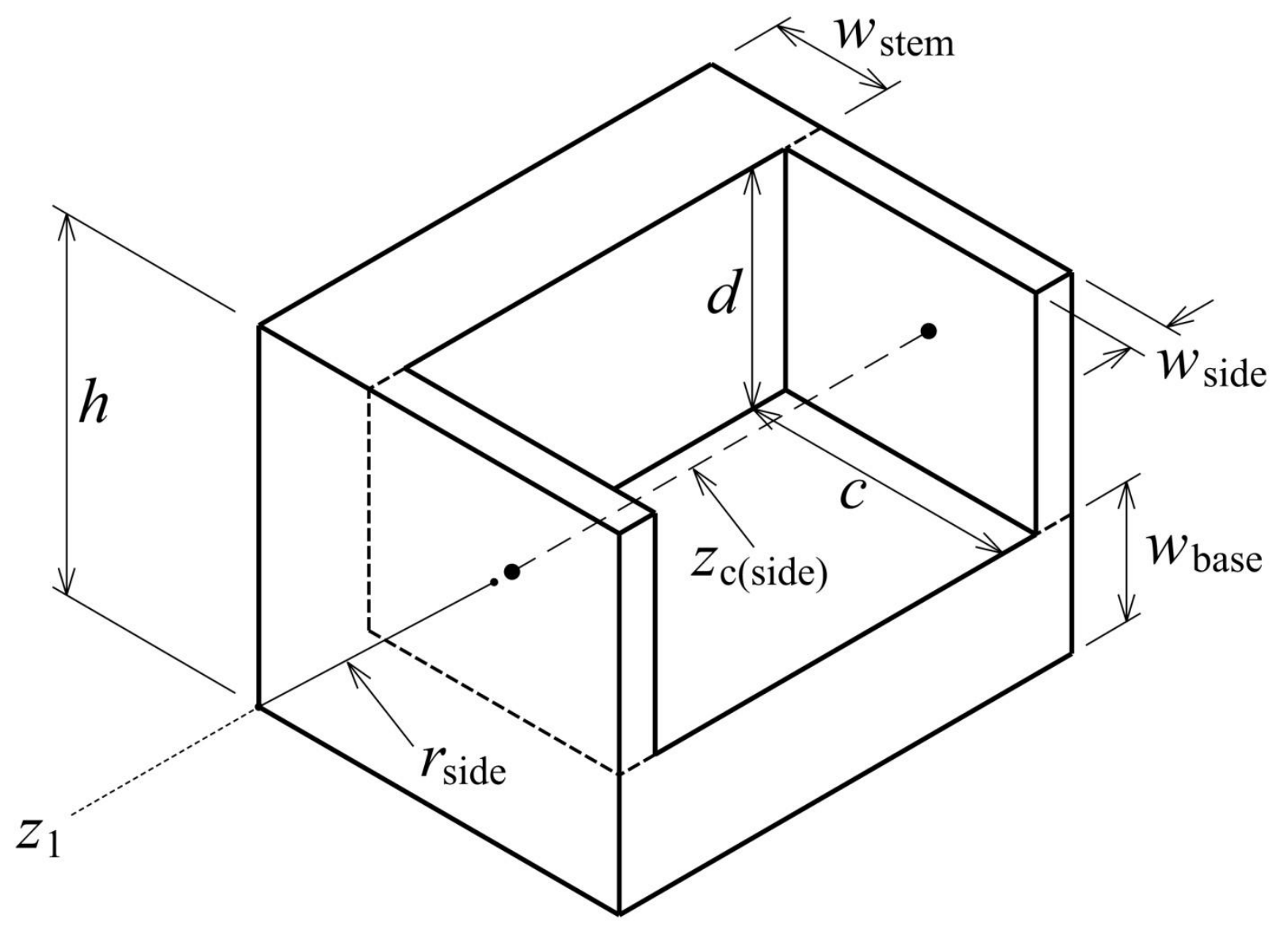




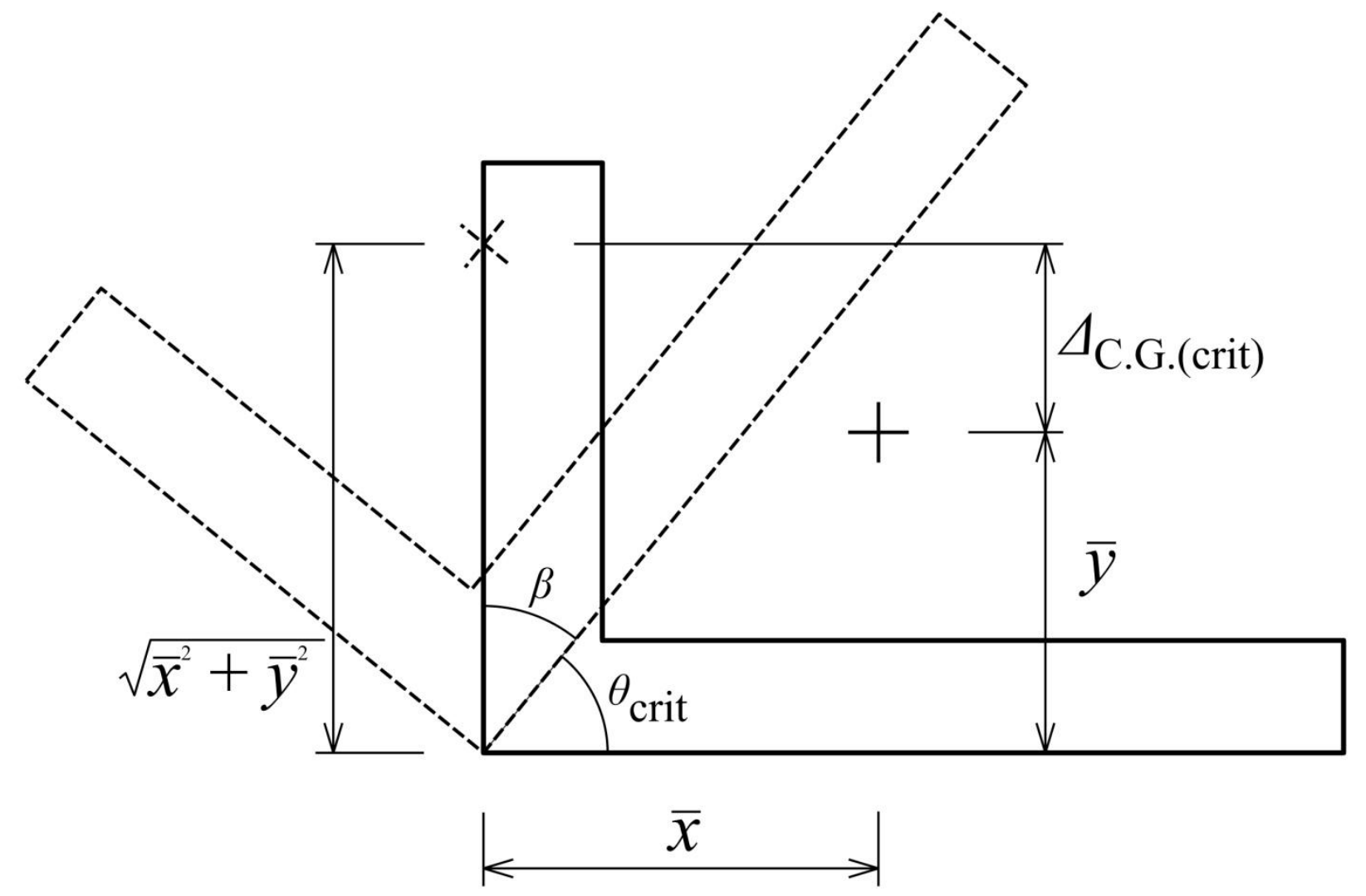




\section{University Library}

\section{- M M N E R VA A gateway to Melbourne's research publications}

Minerva Access is the Institutional Repository of The University of Melbourne

Author/s:

Lam, C;Yong, ACY;Kwan, JSH;Lam, NTK

Title:

Overturning stability of L-shaped rigid barriers subjected to rockfall impacts

Date:

2018-07-01

Citation:

Lam, C., Yong, A. C. Y., Kwan, J. S. H. \& Lam, N. T. K. (2018). Overturning stability of Lshaped rigid barriers subjected to rockfall impacts. LANDSLIDES, 15 (7), pp.1347-1357. https://doi.org/10.1007/s10346-018-0957-5.

Persistent Link:

http://hdl.handle.net/11343/282821 